\title{
Activation of the mitochondrial caspase pathway and subsequent calpain activation in monkey RPE cells cultured under zinc depletion
}

E Nakajima ${ }^{1,2}$, KB Hammond $^{1,2}$, TR Shearer ${ }^{2}$ and M Azuma ${ }^{1,2}$

\begin{abstract}
Purpose Decreased zinc levels in the macula are reported in patients with age-related macular degeneration, and the zinc chelator $\mathrm{N}, \mathrm{N}, \mathrm{N}^{\prime}$, $\mathrm{N}^{\prime}$-tetrakis (2- pyridylmethyl) ethylenediamine) (TPEN) causes death of human retinal pigment epithelial (RPE) cells. The purpose of the present study was to investigate signal transduction pathways during cell death initiated by TPEN, using monkey RPE cells. Methods RPE cells were cultured with TPEN. Activation of calpains and caspases, and proteolysis of their substrates were detected by immunoblotting. Incubation of calpain inhibitor SNJ-1945 or caspase inhibitor z-VAD-fmk was used to confirm activation of specific proteases.

Results TPEN caused a time-dependent decrease in viable RPE cells. Cell death was accompanied by activation of calpain-1, caspase-9, and caspase-3. SNJ-1945 inhibited calpain activation and slightly inhibited caspase-9 activation. z-VAD-fmk inhibited caspases and calpain-1 activation. TPEN did not activate caspase-12.

Conclusions Relative zinc deficiency in RPE cells causes activation of cytosolic calpain and mitochondrial caspase pathways without ER stress.
\end{abstract}

Eye (2014) 28, 85-92; doi:10.1038/eye.2013.239; published online 8 November 2013

Keywords: calpain; caspase; monkey; non-human primate; AMD; zinc depletion

\section{Introduction}

The retinal pigment epithelium (RPE) is an outer, single layer of cells overlaying the neural retina. RPE functions include formation of the outer blood-retinal barrier, transport of nutrients to photoreceptors, stabilization of the ion composition in the sub-retinal space, transport and storage of retinoids, phagocytosis and degradation of spent outer segments, protection against light and free radicals, and production of growth factors. ${ }^{1}$ These complex RPE functions are essential for visual function.

Abnormalities of RPE and Bruch's membrane lead to macular degeneration characterized by a progressive loss of the central vision. ${ }^{2}$ Age-related macular degeneration (AMD) is the principle cause of incurable blindness throughout the world. The two types of AMD are the dry and wet forms, a classification based on the absence or presence of choroidal neovascularization $(\mathrm{CNV}) . \mathrm{CNV}$ is comprised of newly formed, immature blood vessels growing from the choroid to the outer retina. Patients typically first develop dry AMD, which is considered a risk factor or a precursor state for wet AMD. In the early stage of AMD, insoluble extracellular aggregates (drusen) accumulate in the retina. ${ }^{3}$ Later stage dry AMD is characterized by geographic atrophy, which is scattered or confluent areas of degenerated RPE cells. These degenerated RPE cells overlay the photoreceptors that rely on the RPE for trophic support. ${ }^{4}$ In later stage wet $\mathrm{AMD}$, the $\mathrm{CNV}$ vessels leak fluid below or into the retina. ${ }^{4}$

The major risk factors for the early stage of AMD include: smoking, low dietary intake of anti-oxidants, and possibly low levels of zinc. ${ }^{4,5}$ These risk factors might cause loss of phagocytosis by the RPE and accumulation of toxic retinal debris which lead to dry AMD. ${ }^{1}$ RPE stress leads to CNV in wet AMD. ${ }^{4}$
'Senju Laboratory of Ocular Sciences, Senju

Pharmaceutical Corporation Limited, Portland, OR, USA

${ }^{2}$ Department of Integrative Biosciences, Oregon Health \& Science University, Portland, OR, USA

Correspondence: M Azuma, Senju Pharmaceutical Corporation Limited, 4640 SW

Macadam Ave., Suite 200C, Portland, OR 97239, USA

Tel: + 15037485202

Fax: + 15037485204

E-mail: azumam@ohsu.edu

Received: 17 June 2013 Accepted in revised form: 26 September 2013 Published online: 8 November 2013 
Knowledge of the molecular mechanisms underlying wet AMD has led to several robust FDA-approved therapies. ${ }^{4}$ However, treatment of wet AMD does not typically ameliorate RPE damage, ${ }^{4}$ and inhibition of the initial stage of the RPE cell damage would be of major benefit in the treatment of AMD.

A detailed molecular mechanism for RPE cell death is lacking. It is known that Oral zinc supplementation ameliorates some symptoms in human AMD. ${ }^{6}$ The membrane-permeable zinc chelator $\mathrm{N}, \mathrm{N}, \mathrm{N}^{\prime}, \mathrm{N}^{\prime}$-tetrakis (2- pyridylmethyl) ethylenediamine) (TPEN) ${ }^{7,8}$ causes cell death in cultured, primary, human RPE cells, where cell death is inhibited by calpain and caspase inhibitors. ${ }^{9,10} \mathrm{~A}$ recent in vivo study shows that zinc deficiency leads to accumulation of lipofuscin fluorophore in rat RPE cells. ${ }^{11}$ The purpose of the present study was to further investigate cell death pathways in monkey RPE cells cultured with TPEN.

\section{Materials and methods}

\section{Experimental animals}

Eyes from 21 rhesus macaques (Macaca mulatta, 1-12 years of age, mean weight $=4.67 \mathrm{~kg}$ ) were obtained at necropsy from the Oregon National Primate Research Center (Beaverton, OR, USA) from experiments unrelated to the present studies. Experimental animals were handled in accordance with the ARVO statement for the Use of Animals in Ophthalmic and Vision Research and with the Guiding Principles in the Care and Use of Animals (DHEW Publication, NIH 80-23). Monkey eyes were utilized because they are similar to human but can be obtained more quickly after death, thus minimizing post-mortem metabolic changes. The average time between death and dissection was less than $1 \mathrm{~h}$.

\section{Primary culture of RPE cells}

Monkey RPE cells were cultured using Tamada's method for human RPE cells. ${ }^{10}$ Briefly, fresh eyecups were quartered, the retinas were removed, and the remaining $\mathrm{RPE} /$ choroid samples were incubated in $20 \mathrm{mg} / \mathrm{ml}$ dispase for $1 \mathrm{~h}$ (Roche Applied Science, Indianapolis, IN, USA). The RPE cells were collected by pipetting, washed in a solution containing $250 \mathrm{U}$ penicillin and $250 \mu \mathrm{g}$ streptomycin $/ \mathrm{ml}$, and plated on a six-well plates (Greiner Bio-One, Monroe, NC, USA) with DMEM (Life Technologies, Grand Island, NY, USA) supplemented with $50 \mathrm{U} / \mathrm{ml}$ penicillin, $50 \mu \mathrm{g} / \mathrm{ml}$ streptomycin, and $15 \%$ fetal bovine serum (FBS, PAA Laboratories, Inc., Dartmouth, MA, USA) at $37^{\circ} \mathrm{C}$ in humidified $95 \%$ air/ $5 \% \mathrm{CO}_{2}$. The cells were trypsinized before passage.
The cells from passage 3 were plated at $10^{4}$ cells $/ \mathrm{cm}^{2}$ on to 6-well or 96-well plates and grown for 5 days before they were used for experiments. RPE cells reached 100\% confluency on day 6 (Figure 1).

\section{Zinc depletion, ER stress, and activation of death receptor pathways}

Chelation of zinc ion was performed by adding $3 \mu \mathrm{M}$ TPEN (Sigma-Aldrich Corp., St Louis, MO, USA) to cultured RPE cells for two days. The time dependent experiment was performed and reported in the Supplementary Information. When used, 10 or $100 \mu \mathrm{M}$ calpain inhibitor SNJ-1945 or $100 \mu \mathrm{M}$ pan-caspase inhibitor z-VAD-fmk (BioVision, Inc., Milpitas, CA, USA) were added $1 \mathrm{~h}$ before the TPEN. Images were captured with an Axiovert 200 microscope and digitalized with an AxioCam MRm camera (Carl Zeiss Vision Gmbh, Hallbergmoos, Germany). The images were processed with ImageJ 1.42 (National Institutes of Health, Bethesda, MD, USA) and Photoshop (Adobe Systems Inc., San Jose, CA, USA).

Fas ligand (EMD Chemicals, Billerica, MA, USA) at $100-500 \mathrm{ng} / \mathrm{ml}$ or $50-500 \mathrm{ng} / \mathrm{ml}$ TNF $\alpha$ (R\&D Systems, Inc., Minneapolis, MN, USA) were used as positive controls for calpain- 8 activation in the death receptor pathway. Ten micrometer thapsigargin (Santa Cruz Biotechnology, Inc., Santa Cruz, CA, USA) was used as a positive control for caspase-12 activation during ER stress. A caspase-12 inhibitor ATAD (R\&D systems, Inc.) was used at $10 \mu \mathrm{M}$.

\section{Protein extraction and immunoblotting}

Total cellular proteins were extracted by sonication in a buffer containing $20 \mathrm{mM}$ Tris (pH 7.5), $5 \mathrm{mM}$ EGTA, $5 \mathrm{mM}$ EDTA, and $2 \mathrm{mM}$ dithioerythritol. Protein concentrations were measured by the BCA assay (Thermo Fisher Scientific Inc., Rockford, IL, USA) with bovine serum albumin standards. For immunoblotting, equal amounts of the proteins were loaded and run on 4-12\% NuPAGE gels

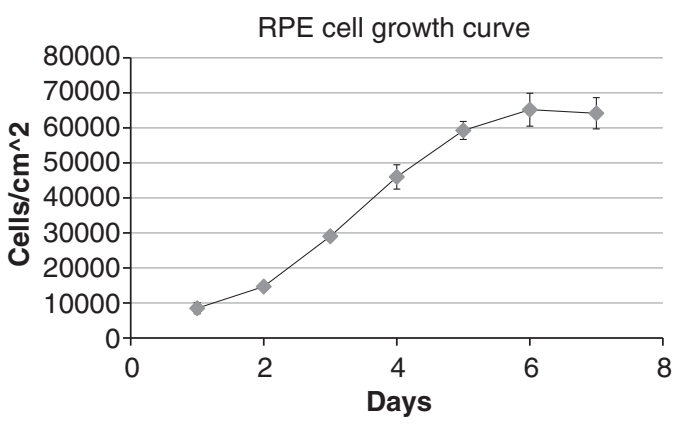

Figure 1 Growth curve for cultured monkey RPE cells. Data are expressed as means \pm SEM $(n=3-5)$. 
with MES or MOPs buffers (Life Technologies).

The proteins were electrotransferred to PVDF membrane at $100 \mathrm{~V}$ for $1 \mathrm{~h}$. The membranes were probed with primary antibodies to calpain-1 (Thermo Fisher Scientific), calpain-2, $\beta$-actin (Sigma-Aldrich), $\alpha$-spectrin, caspase-7 (Enzo Life Sciences, Inc., Farmingdale, NY, USA), cytokeratin-18, caspase-3, caspase-8, PARP, vimentin
(Santa Cruz Biotechnology), CHOP, BiP, calnexin (Cell Signaling Technology, Inc., Danvers, MA, USA), caspase-12 (Abcam, Inc., Cambridge, MA, USA), and caspase-9 (EMD Chemicals). Secondary antibodies, conjugated to alkaline phosphatase or to horseradish peroxidase were visualized with BCIP/NBT (Bio-Rad Laboratories, Hercules, CA, USA) or by chemiluminescence (Amersham

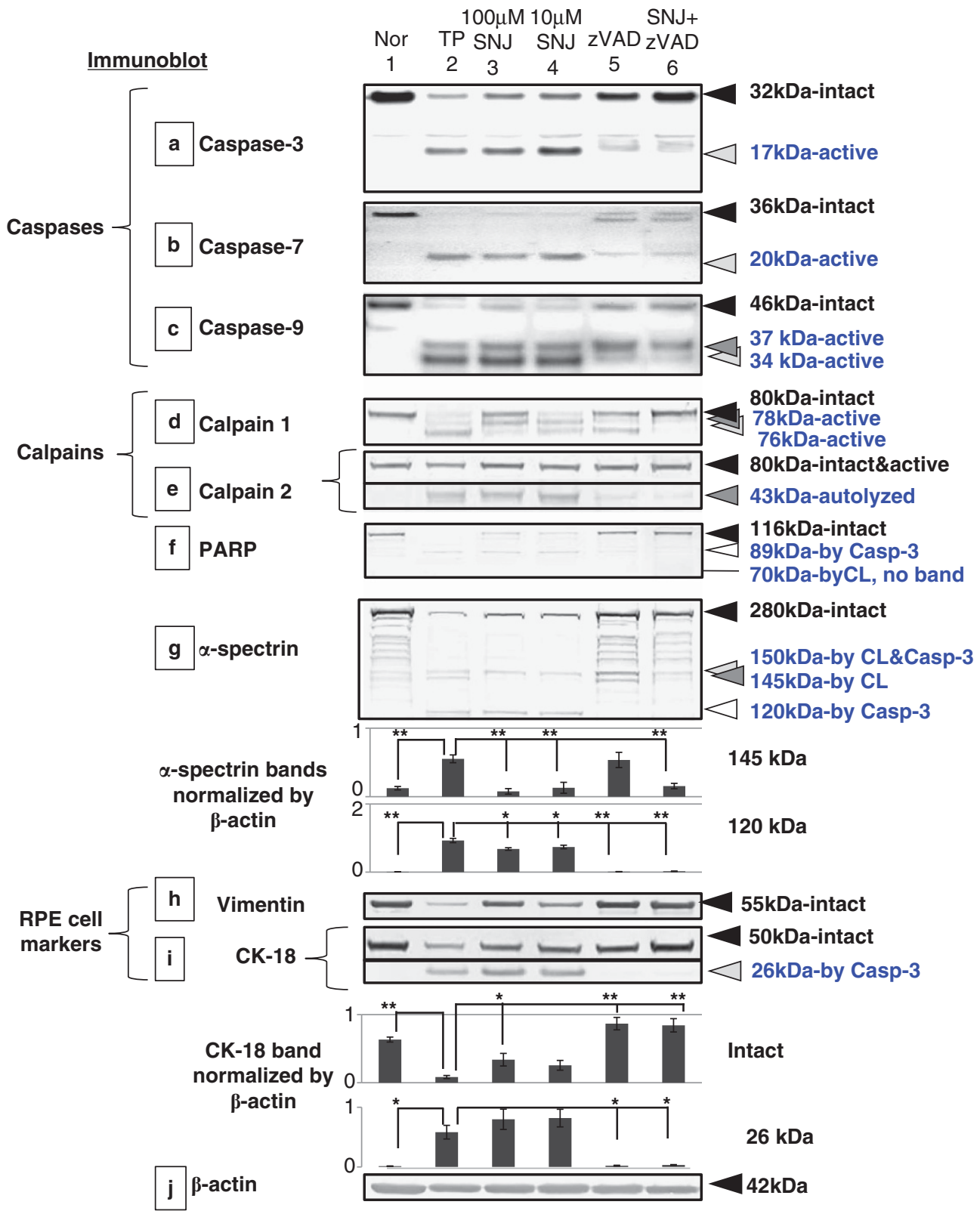

Figure 2 Immunoblots of caspases, calpains, and their substrates: (lane 1) normal, (lane 2) 2-day $3 \mu \mathrm{M}$ TPEN, (lane 3) 2-day $3 \mu \mathrm{M}$ TPEN + $100 \mu \mathrm{M}$ SNJ-1945, (lane 4) 2-day $3 \mu \mathrm{M}$ TPEN + $10 \mu \mathrm{M}$ SNJ-1945, (lane 5) 2-day $3 \mu \mathrm{M}$ TPEN + $100 \mu \mathrm{M} z$-VAD, and (lane 6) 2-day $3 \mu \mathrm{M}$ TPEN $+100 \mu \mathrm{M}$ SNJ-1945 + $100 \mu \mathrm{M}$ z-VAD. (a) caspase-3, (b) caspase-7, (c) caspase-9, (d) calpain-1, (e) calpain-2, (f) PARP, (g) caspase- 3 and calpain substrate, $\alpha$-spectrin, (h) RPE cell marker - vimentin, (i) RPE cell marker-cytokeratin-18, and (j) $\beta$-actin. (g) The bar graph shows the density of the $\alpha$-spectrin $145 \mathrm{kDa}$ band (calpain-specific) and the $120 \mathrm{kDa}$ band (caspase-3-specific) normalized to $\beta$-actin, and (i) the density of the cytokeratin-18 intact band and the $26 \mathrm{kDa}$ band (caspase- 3 -specific) normalized to $\beta$-actin and expressed as means \pm SEM $(n=3)$. ${ }^{* *} P<0.01$ and ${ }^{*} P<0.05$, all relative to TPEN (Dunnett's $t$-test). 
ECL Plus, GE Healthcare Biosciences, Piscataway, NJ, USA). Band intensities were measured with ImageJ 1.40 (NIH, Bethesda, MD, USA). To compensate for staining variability between the membranes, densities of the bands were normalized to the density of $\beta$-actin loading control. Statistical analyses were performed by Dunnett's $t$-test (JMP 8.0.1 Statistical Software, SAS Institute Inc., Cary, NC, USA). Three independent experiments from different cultures were conducted for all the studies.

We certify that all applicable institutional and governmental regulations concerning the ethical use of animals were followed during this research.

\section{Results}

\section{Caspase and calpain activation in zinc depletion}

In the TPEN-treated cells, endogenous pro-caspase 3 at $32 \mathrm{kDa}$ was proteolyzed to an active $17 \mathrm{kDa}$ fragment. ${ }^{12}$ A smaller active caspase- 3 fragment at $12 \mathrm{kDa}$, which is known to form the active caspase- 3 hetero-dimer with an $17 \mathrm{kDa}$ fragment, ${ }^{12}$ was not detected. Known inactive caspase- 3 fragments at 29 and $24 \mathrm{kDa}$ caused by calpain ${ }^{13}$ were not present (Figure 2a, lanes 1 and 2).

Activation of calpains is associated with autolysis. ${ }^{14}$ The intact $80 \mathrm{kDa}$ catalytic subunit associated with low calcium-requiring calpain-1 decreased after TPEN treatment, and active autolytic fragments at 78 and $76 \mathrm{kDa}$ appeared (Figure 2d, lanes 1 and 2). The 80-kDa catalytic subunit of high calcium-requiring calpain-2 did not appear to change with TPEN treatment (Figure 2e, lanes 1 and 2). However, because the active, N-terminal truncated form of calpain-2 migrates to nearly the same position as the intact $80 \mathrm{kDa}$ calpain- 2 on SDS-PAGE, ${ }^{15}$ the $80 \mathrm{kDa}$ band in lane 2 probably contained both intact and autolyzed calpain-2. In support of this, autolyzed calpain-2 at $43 \mathrm{kDa}$ increased.

The zinc depletion also caused a loss of the intact $280 \mathrm{kDa} \alpha$-spectrin substrate that is hydrolyzed by both caspase-3 and calpains (Figure 2g, lanes 1 and 2). This leads to a significant accumulation of a calpain-specific $145 \mathrm{kDa}$ fragment $(P=0.006, n=3)$ (dark gray arrow head, bar graph) and a caspase-3-specific $120 \mathrm{kDa}$ fragment $(P=0.005, n=3)$ (open arrow head, bar graph). $\beta$-actin was used as an internal loading control (Figure 2j). These results showed that $3 \mu \mathrm{M}$ TPEN causes activation of both caspase-3 and calpain in cultured monkey RPE.

\section{Evaluation of caspase and calpain inhibitors for protection of $R P E$}

TPEN caused severe cell shrinkage which is known to lead apoptosis. ${ }^{16}$ In our studies, cell shrinkage still occurred in the presence of calpain inhibitor SNJ-1945
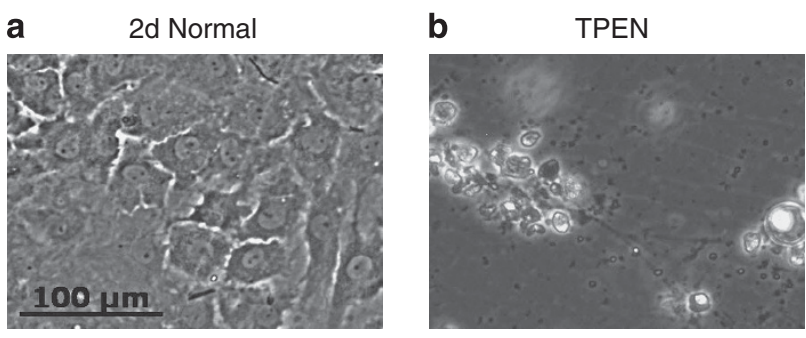

CTPEN + $100 \mu \mathrm{M}$ SNJ-1945 (calpain inhibitor)

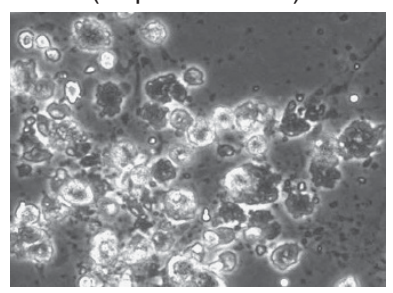

d TPEN + $100 \mu \mathrm{M} z \mathrm{VAD}$ (caspase inhibitor)
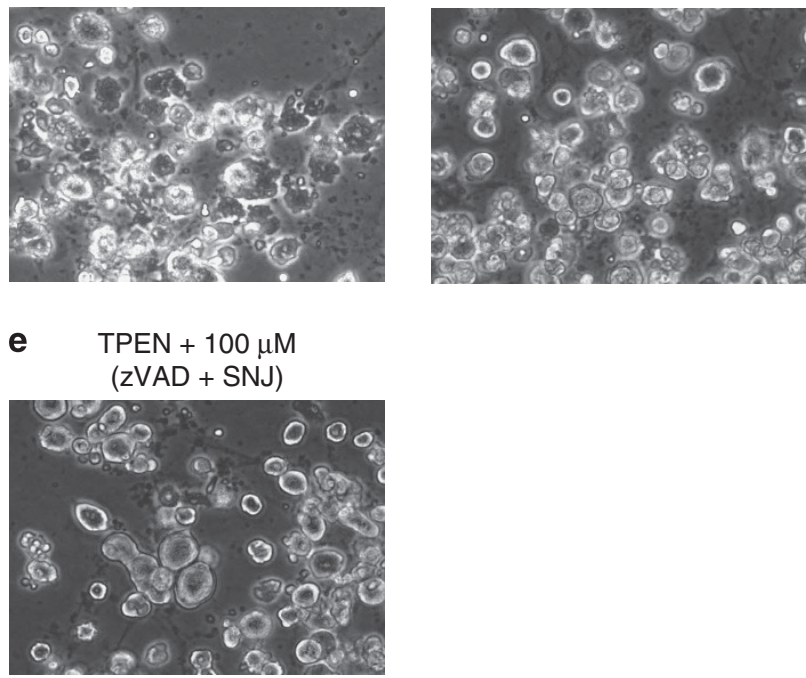

Figure 3 Phase-contrast micrographs of monkey RPE cells: (a) 2-day normal, (b) $3 \mu \mathrm{M}$ TPEN at day 2, (c) $3 \mu \mathrm{M} \mathrm{TPEN}+100 \mu \mathrm{M}$ SNJ-1945 (calpain inhibitor), (d) $3 \mu \mathrm{M}$ TPEN $+100 \mu \mathrm{M}$ z-VAD (caspase inhibitor), and (e) $3 \mu \mathrm{M}$ TPEN $+100 \mu \mathrm{M}$ SNJ$1945+100 \mu \mathrm{M} \mathrm{z}$-VAD.

and caspase inhibitor z-VAD, but the shrunken cells were not lost (Figures 3a-d). Adding SNJ-1945 and z-VAD together did not further protect the cells (Figure 3e), suggesting that either calpain or caspase- 3 is up-stream of the other. We found that the z-VAD partially inhibited the calpain-1 and -2 activation as well as the caspase activation (Figures $2 \mathrm{a}-\mathrm{g}$ ), although the $\mathrm{z}$-VAD did not inhibit accumulation of the calpain-specific $145 \mathrm{kDa} \alpha$ spectrin fragment. Calpain inhibitor SNJ-1945 inhibited the calpain-2 activation (Figures $2 \mathrm{a}-\mathrm{g}$ ) and only weakly inhibited the calpain-1 activation.

In the cultured RPE cells, our TPEN treatment caused loss of the well-known calpain and caspase substrate PARP, migrating at the $116 \mathrm{kDa}$ position (Figure $2 \mathrm{f}$ ). This lead to accumulation of a caspase-3-specific breakdown product at $89 \mathrm{kDa}$ (a marker of apoptosis, ${ }^{17}$ open arrowhead). The calpain-specific $70 \mathrm{kDa}$ breakdown product of PARP was not observed even when calpain was activated. Since the calpain and caspase inhibitors were both able to partially inhibit the TPEN-induced 
morphologic damage at a similar rate (Figures $3 c$ and d), cell death by the TPEN may be due to apoptosis and necrosis by action of calpain and caspase. Densitometric analysis showed: significant inhibition of the accumulation of the calpain-specific $145 \mathrm{kDa}$ SBDP by the calpain inhibitor (SNJ $100 \mu \mathrm{M}, P=0.008$; SNJ $10 \mu \mathrm{M}$, $P=0.015, n=3$ ) but not by the caspase inhibitor $(P=1.000, n=3)$ (Figure $2 \mathrm{~g}$, upper graph), significant inhibition of accumulation of the caspase-specific $120 \mathrm{kDa}$ SBDP by the caspase inhibitor $(P<0.001, n=3)$, and only minor inhibition by the calpain inhibitor (SNJ $100 \mu \mathrm{M}, P=0.007$; SNJ $10 \mu \mathrm{M}, P=0.028, n=3$ ) (Figure 2g lower graph). $\beta$-actin was used as an internal loading control (Figure 2j).

The densities of protein bands for RPE cell markers, vimentin $^{18,19}$ (Figure 2h) and cytokeratin-18 (Figure 2i), decreased or were fragmented in the RPE cells cultured with TPEN. Vimentin is expressed in primate RPE cells in vivo only under pathologic conditions but is expressed in culture. ${ }^{19}$ The loss of the cytokeratin-18 intact band is statistically significant $(P=0.001, n=3)$. One hundred micrometer SNJ-1945 caused partial rescue, and $z$-VAD promoted full recovery of the intact bands for both vimentin and cytokeratin-18.
The accumulation of caspase-3-specific cytokeratin-18 at $26 \mathrm{kDa}$ was fully inhibited by the z-VAD (lanes 5 and 6). SNJ-1945 did not inhibit production of the $26 \mathrm{kDa}$ band (lanes 3 and 4).

\section{Caspase-8 death receptor and caspase-12 ER stress pathways}

Caspases (including caspase-8) or calpains were not activated by up to $500 \mathrm{ng}$ Fas ligand or TNF $\alpha / \mathrm{ml}$ (data not shown). As a positive control, stress inducer $10 \mu \mathrm{M}$ thapsigargin activated ER caspase-12 (Figure 4a), other caspases (-3 and -9 , data not shown), and calpains (Figures $4 \mathrm{~b}$ and $\mathrm{c}$ ). An ER membrane marker, calnexin, decreased after the thapsigargin treatment (Figure 4e). CHOP and BiP levels in our experiments increased with the thapsigargin treatment (Figures $4 \mathrm{f}$ and $\mathrm{g}$ ).

The caspase-12 inhibitor ATAD inhibited the caspase-12 activation and ER stress (lane 3 ). $\beta$-actin was used as an internal loading control (Figure 4h).

In contrast, TPEN did not cause ER stress or caspase-12 activation (lane 5), and caspase-12 inhibitor was not able to inhibit the TPEN-mediated calpain and caspase activation (Figures $4 b-d$, lane 6).

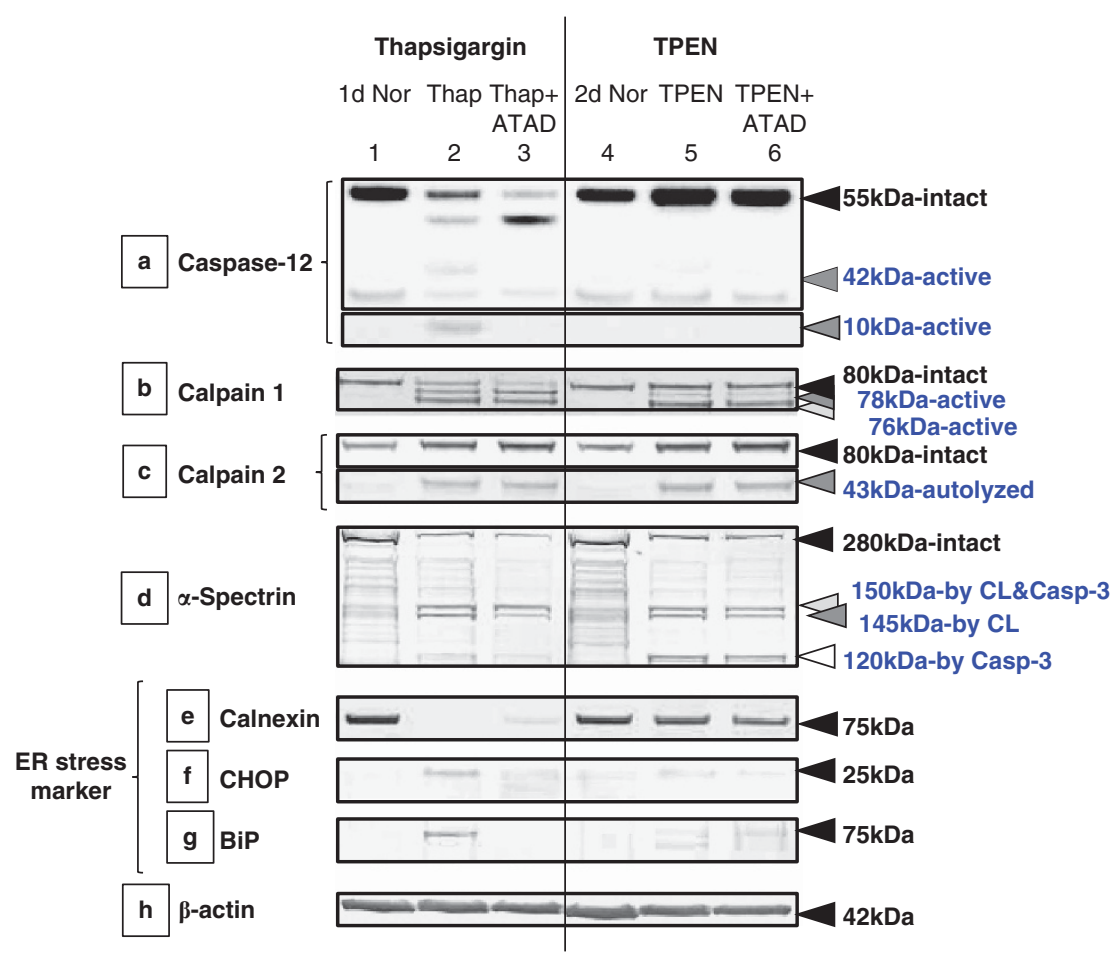

Figure 4 Immunoblots for ER caspase, caspase-12, calpains, $\alpha$-spectrin, and ER stress markers: (lanes 1-3) ER stress marker treated with thapsigargin and (lanes 4-6) treated with TPEN. (Lane 1) 1-day normal, (lane 2) 1-day $10 \mu \mathrm{M}$ thapsigargin, (lane 3) 1-day $10 \mu \mathrm{M}$ thapsigargin $+100 \mu \mathrm{M}$ SNJ-1945, (lane 4) 2-day normal, (lane 5) 2-day $3 \mu \mathrm{M} \mathrm{TPEN}$, and (lane 6) 2-day $3 \mu \mathrm{M} \mathrm{TPEN}+100 \mu \mathrm{M}$ SNJ-1945. (a) Caspase-12, (b) calpain-1, (c) calpain-2, (d) caspase-3 and calpain substrate $\alpha$-spectrin, (e) ER membrane marker calnexin, (f) ER stress marker CHOP, (g) ER stress marker Bip, and (h) $\beta$-actin. 


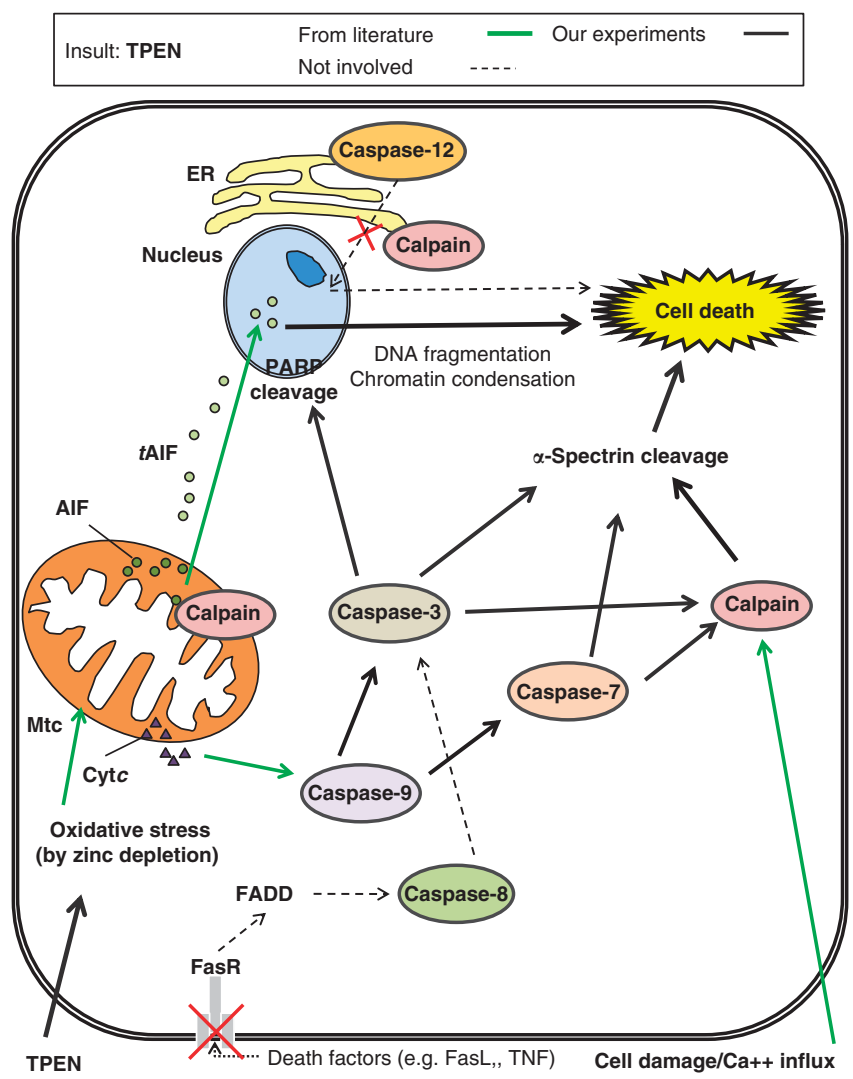

Figure 5 Proposed pathways leading to TPEN-induced cell death in monkey RPE cells due to activation of caspases and calpains. Solid lines show the pathways confirmed in present study, green lines show the pathways reported in the literature, ${ }^{22,26,27}$ and dotted lines show the pathways not involved after TPEN treatment.

\section{Discussion}

Understanding which enzymes cause the death of RPE cells in AMD is important because such knowledge may facilitate the development of drugs to regulate their activity. Using our monkey model of RPE cell death, the present studies showed that: (1) cytosolic calpains are activated (confirming previous studies in human cells ${ }^{10}$ ), (2) the mitochondrial caspase pathway is activated, and (3) the ER stress and death receptor pathways are not involved in TPEN-induced damage.

We speculate that a major mechanism for the TPEN damage in the current study was zinc deficiency. However, note that in addition to zinc, TPEN chelates other heavy metal ions (eg copper and iron). Manganese is a key component of mitochondrial superoxide dismutase 2, and manganese deficiency causes cell damage in the RPE. ${ }^{20}$ The AREDS (Age-Related Eye Disease Study) ${ }^{6}$ shows that reduced zinc and copper are risk factors for AMD. Thus, deficiency of other metal ions might also contribute to the observed RPE cell damage.
Caspase activation generally indicates apoptotic cell death. ${ }^{21}$ The fact that initiator caspase-9, and effecter caspases- 3 and -7 were activated by our TPEN treatments also suggests that the RPE cell damage is caused by damage to mitochondria. ${ }^{22}$ As indicated in the summary of pathways involved in TPEN-induced cell death (Figure 5), initial zinc deficiency may have caused early mitochondrial damage by oxidative stress. This was supported by the fact that zinc is a co-factor for $\mathrm{Cu}-\mathrm{Zn}$ superoxide dismutase. ${ }^{23}$ Adequate zinc also induces the synthesis of cysteine-rich metallothionein, a hydroxyl radical scavenger. ${ }^{24}$

Once pro-apoptotic signals such as the Bcl-2 proteins translocate to mitochondria, intramembrane cytochrome c (Cyt c) moves into the cytosol. ${ }^{22}$ Cyt c activates caspase- 9 by forming an apoptosome APAF-1 complex (Cyt c + pro-caspase-9). This activates effecter caspases-3 and -7 (Figure 5). In our study, pan-caspase inhibitor z-VAD blocked caspase and calpain activation (Figures $3 a-g$, lane 6), suggesting that the substrates of caspases contribute to the initial stage of the apoptotic cascade. In contrast, when the RPE cells were pretreated with 
calpain inhibitor SNJ-1945 prior to TPEN treatment, the SNJ-1945 was not able to inhibit caspase activation (Figures $3 \mathrm{a}-\mathrm{g}$, lanes 3 and 4 ). The ability of $\mathrm{z}$-VAD to effectively block caspase function as well as the calpain activation suggests that calpain activation may be a caspase-dependent event. A similar situation is observed in HL-60 cells treated with topoisomerase I inhibitor 9-AC. ${ }^{25}$ However, z-VAD in our experiments was not able to inhibit formation of the calpain-specific $145 \mathrm{kDa}$ SBDP, which suggests that calpain and caspase pathways may run in parallel.

We hypothesize that calpain is activated by caspases directly and/or by increased calcium influx due to cell injury inflicted by zinc deficiency. ${ }^{10}$ Caspases and calpains proteolyzed cytoskeletal proteins such as $\alpha$-spectrin, vimentin, and cytokeratin 18 , leading to severe cell damage and cell death in the zinc-deficient RPE cells. Furthermore, apoptosis-inducible factor (AIF) released from mitochondria is part of a well-studied caspaseindependent pathway. ${ }^{26,27}$ Calpain-induced truncation of AIF is released from the inner mitochondrial membrane and translocated to the nucleus, where it causes chromatin condensation. Apoptotic ER stress activates caspase- 12 through calpain action, ${ }^{27}$ but this was not observed in our monkey RPE cells (Figure 4). Since caspase activation generally indicates apoptotic cell death, further investigation is necessary to determine if the calpain activation also contributed to the necrosis/ apoptosis in our TPEN-treated macula.

Our studies in an in vitro model with retinal pigment epithelial cells from monkeys support the hypothesis that drug inhibition of cytosolic calpains and mitochondrial caspases in RPE may be useful in the treatment of AMD.

\section{Summary}

What was known before:

- Low levels of zinc have been reported in the macula patients with age-related macular degeneration (AMD), and oral zinc supplementation ameliorated some symptoms.

- The membrane-permeable zinc chelator TPEN caused cell death in cultured, primary, human retinal pigment epithelium (RPE) cells, and cell death was inhibited by calpain and caspase inhibitors.

What this study adds:

- Relative zinc deficiency in monkey RPE cells causes activation of the cytosolic calpain pathway and the mitochondrial caspase pathway without ER stress.

\section{Conflict of interest}

The authors declare no conflict of interest.

\section{Acknowledgements}

Dr Shearer is a paid consultant for Senju Pharmaceutical Co, Ltd, a company that may have a commercial interest in the results of this research and technology. Drs Azuma and Nakajima are employees of Senju Pharmaceutical Co, Ltd. This potential conflict of interest was reviewed, and a management plan approved by the OHSU Conflict of Interest in Research Committee was implemented. This research was supported in part by NIH grant RR00163 to the Oregon National Primate Research Center.

\section{References}

1 Strauss O. The retinal pigment epithelium in visual function. Physiol Rev 2005; 85: 845-881.

2 Piguet B, Haimovici R, Bird AC. Dominantly inherited drusen represent more than one disorder: a historical review. Eye (Lond) 1995; 9(Pt 1): 34-41.

3 Azuma MCK, Fujii A, Shearer TR. Patient selection criteria for pilot studies on amelioration of non-neovascular age-related macular degeneration. J Ocul Pharmacol Ther 2010; 26: 367-371.

4 Ambati J, Fowler BJ. Mechanisms of age-related macular degeneration. Neuron 2012; 75: 26-39.

5 Newsome DA, Miceli MV, Tate Jr DJ, Alcock NW, Oliver PD. Zinc content of human retinal pigment epithelium decreases with age and macular degeneration, but superoxide dismutase activity increases. J Trace Elem Exp Med 1995; 8: 193-199.

6 Group A-REDSR. A randomized, placebo-controlled, clinical trial of high-dose supplementation with vitamins $C$ and $\mathrm{E}$, beta carotene, and zinc for age-related macular degeneration and vision loss: AREDS report no. 8. Arch Ophthalmol 2001; 119: 1417-1436.

7 McCabe Jr MJ, Jiang SA, Orrenius S. Chelation of intracellular zinc triggers apoptosis in mature thymocytes. Lab Invest 1993; 69: 101-110.

8 Nakatani T, Tawaramoto M, Opare Kennedy D, Kojima A, Matsui-Yuasa I. Apoptosis induced by chelation of intracellular zinc is associated with depletion of cellular reduced glutathione level in rat hepatocytes. Chem Biol Interact 2000; 125: 151-163.

9 Hyun HJ, Sohn JH, Ha DW, Ahn YH, Koh JY, Yoon YH. Depletion of intracellular zinc and copper with TPEN results in apoptosis of cultured human retinal pigment epithelial cells. Invest Ophthalmol Vis Sci 2001; 42: 460-465.

10 Tamada Y, Walkup RD, Shearer TR, Azuma M. Contribution of calpain to cellular damage in human retinal pigment epithelial cells cultured with zinc chelator. Curr Eye Res 2007; 32: 565-573.

11 Julien S, Biesemeier A, Kokkinou D, Eibl O, Schraermeyer U. Zinc deficiency leads to lipofuscin accumulation in the retinal pigment epithelium of pigmented rats. PLoS One 2011; 6: e29245.

12 Nicholson DW, Ali A, Thornberry NA, Vaillancourt JP, Ding CK, Gallant $\mathrm{M}$ et al. Identification and inhibition of the ICE/CED-3 protease necessary for mammalian apoptosis. Nature 1995; 376: 37-43. 
13 Nakajima E, Hammond KB, Rosales JL, Shearer TR, Azuma M. Calpain not caspase, is the causative protease for hypoxic damage in cultured monkey retinal cells. Invest Ophthalmol Vis Sci 2011; 52: 7059-7067.

14 Kitagaki H, Tomioka S, Yoshizawa T, Sorimachi H, Saido TC, Ishiura $S$ et al. Autolysis of calpain large subunit inducing irreversible dissociation of stoichiometric heterodimer of calpain. Biosci Biotechnol Biochem 2000; 64: 689-695.

15 Azuma M, Fukiage C, David LL, Shearer TR. Activation of calpain in lens: a review and proposed mechanism. Exp Eye Res 1997; 64: 529-538.

16 Krampe B, Al-Rubeai M. Cell death in mammalian cell culture: molecular mechanisms and cell line engineering strategies. Cytotechnology 2010; 62: 175-188.

17 Oliver FJ, de la Rubia G, Rolli V, Ruiz-Ruiz MC, de Murcia G, Murcia JM. Importance of poly(ADP-ribose) polymerase and its cleavage in apoptosis. Lesson from an uncleavable mutant. I Biol Chem 1998; 273(50): 33533-33539.

18 Mamballikalathil I, Mann C, Guidry C. Tractional force generation by porcine Müller cells: paracrine stimulation by retinal pigment epithelium. Invest Ophthalmol Vis Sci 2000; 41: 529-536.

19 Matsumoto B, Guérin CJ, Anderson DH. Cytoskeletal redifferentiation of feline, monkey, and human RPE cells in culture. Invest Ophthalmol Vis Sci 1990; 31(5): 879-889.
20 Sandbach JM, Coscun PE, Grossniklaus HE, Kokoszka JE, Newman NJ, Wallace DC. Ocular pathology in mitochondrial superoxide dismutase (Sod2)-deficient mice. Invest Ophthalmol Vis Sci 2001; 42: 2173-2178.

21 Wang KK. Calpain and caspase: can you tell the difference? Trends Neurosci 2000; 23: 20-26.

22 Bayir H, Kagan VE. Bench-to-bedside review: mitochondrial injury, oxidative stress and apoptosis - there is nothing more practical than a good theory. Crit Care 2008; 12: 206.

23 Marklund SL, Westman NG, Lundgren E, Roos G. Copper- and zinc-containing superoxide dismutase, manganese-containing superoxide dismutase, catalase, and glutathione peroxidase in normal and neoplastic human cell lines and normal human tissues. Cancer Res 1982; 42: 1955-1961.

24 Sato M, Bremner I. Oxygen free radicals and metallothionein. Free Radic Biol Med 1993; 14: 325-337.

25 Wood DE, Newcomb EW. Caspase-dependent activation of calpain during drug-induced apoptosis. J Biol Chem 1999; 274: 8309-8315.

26 Cregan SP, Dawson VL, Slack RS. Role of AIF in caspasedependent and caspase-independent cell death. Oncogene 2004; 23: 2785-2796.

27 Sanges D, Comitato A, Tammaro R, Marigo V. Apoptosis in retinal degeneration involves cross-talk between apoptosisinducing factor (AIF) and caspase-12 and is blocked by calpain inhibitors. Proc Natl Acad Sci USA 2006; 103: 17366-17371.

Supplementary Information accompanies this paper on Eye website (http://www.nature.com/eye) 